\title{
Improving redox sensitivity of roGFP1 by incorporation of selenocysteine at position 147
}

\author{
Katherine R. Stanford, Joanne M. Ajmo, Parmvir K. Bahia, Stephen H. Hadley and Thomas E. Taylor-Clark* (1)
}

\begin{abstract}
Objective: Redox-sensitive green fluorescent protein (roGFP) is a genetically-encoded redox-sensitive protein used to detect cellular oxidative stress associated with reactive oxygen species production. Here we replaced the cysteine at position 147 of roGFP1 (variant of roGFP) with selenocysteine in order to increase redox sensitivity of the redox reporter.

Results: Expression of roGFP1 selenoprotein (roGFP1-Se147) in HEK293 cells required the presence of a selenocysteine insertion sequence and was augmented by co-expression with SBP2. roGFP1-Se147 demonstrated a similar excitation and emission spectra to roGFP1. Although expression of roGFP1-Se147 was limited, it was sufficient enough to perform live cell imaging to evaluate sensitivity to oxidation and reduction. roGFP1-Se147 exhibited a 100-fold increase in sensitivity to oxidation with $\mathrm{H}_{2} \mathrm{O}_{2}$ in comparison to roGFP1 as well as a 20-fold decrease in the $\mathrm{EC}_{50}$ of $\mathrm{H}_{2} \mathrm{O}_{2}$. Furthermore, roGFP1-Se147, unlike roGFP1, was able to detect oxidation caused by the mitochondrial electron transport complex III inhibitor antimycin A. Unfortunately roGFP-Se147 exhibited a diminished dynamic range and photoinstability.
\end{abstract}

Keywords: Green fluorescent protein, Reporter, Redox-sensing, Selenocysteine, Reactive oxygen species

\section{Introduction}

Investigations into reactive oxygen species (ROS) signaling has been hindered by a lack of available methods to accurately measure small and localized ROS fluctuations. Unfortunately, redox-sensitive dyes often lack the ability to localize in sub-cellular compartments and are generally incompatible with in vivo use. Genetically-encoded reporter proteins such as redox-sensitive green fluorescent protein (roGFP) have been used in vivo and targeted to many organelles, but they lack the sensitivity of dyes [1-5]. Although roGFP2 is sensitive to hypoxia-mediated ROS production, its responses are slow $[1,6]$, suggesting significant limitations for the detection of local,

*Correspondence: ttaylorc@health.usf.edu

Department of Molecular Pharmacology \& Physiology, Morsani College

of Medicine, University of South Florida, 12901 Bruce B Downs Blvd,

Tampa, FL 33612, USA small-scale, and transient fluctuations involved in physiologic ROS signaling.

roGFP1 is a commonly used variant of roGFP that is largely unaffected by $\mathrm{pH}$ and produces a strong fluorescent signal [7]. roGFP1 contains two redox-sensitive cysteines at amino acids 147 and 204 which serve as a biological switch. Oxidation and reduction of these cysteines shifts fluoresce between two excitation maxima (405 and $470 \mathrm{~nm}$ ) [1, 8]. As such, redox state is expressed as a ratio of these excitation maxima (405/470). Upon exposure to an oxidative environment (either ROS or oxidized glutathione), the redox-sensitive cysteines are oxidized, resulting in intramolecular disulfide bond formation, increased fluorescence at $405 \mathrm{~nm}$ and decreased fluorescence at $470 \mathrm{~nm}$ (increased 405/470 ratio) [8]. Reduced glutathione reduces the disulfide bond, restoring fluorophore structure and fluorescent properties to the pre-oxidized state. 
Despite these ratiometric and reversible properties, roGFP's lack of sensitivity renders it unsuitable for detecting ROS fluctuations involved in physiologic signaling [1]. One factor contributing to its relative insensitivity is the protonation of its redox-sensitive cysteines under physiologic cellular conditions: only deprotonated cysteines are able to react with ROS [9]. To overcome this barrier, several attempts have been made to decrease the pKa (from 8.2) of the roGFP1 cysteines by mutating surrounding amino acids [10]. Unfortunately, the resulting proteins also lacked the sensitivity to detect small ROS fluctuations. An alternative approach to increase the sensitivity of roGFP1 is to replace the relevant cysteines with selenocysteine, a more reactive nucleophile with a lower pKa (5.5 vs 8.2) [11]. Selenocysteine is capable of forming bridges upon oxidation with either selenocysteine or cysteine [12].

Selenocysteine incorporation into proteins is complex and inefficient compared to insertion of canonical amino acids. Selenocysteine incorporation occurs at UGA codons, which typically serve to stop protein translation [13]. Thus, incorporation requires additional elements including a selenocysteine insertion sequence (SECIS) in the $3^{\prime}$ untranslated region of the mRNA and a selenocysteine specific elongation factor [14-17]. Here we attempted to increase the sensitivity of roGFP1 by mutating the functional cysteine (at position 147) to selenocysteine (roGFP1-Se147). Though roGFP1-Se147 demonstrated increased ROS sensitivity, it exhibited a poor dynamic range and photoinstability.

\section{Main text}

Methods and results

All roGFP constructs were derived from roGFP1-N1 [7] (Additional file 1: Methods). To maximize selenoprotein expression, we used two systems for expression of the roGFP1 selenoprotein (roGFP1-Se147): pLuc01 and pSel. Both selenoprotein expression vectors (selenovectors) contained a $3^{\prime}$ SECIS element. To increase selenocysteine incorporation, roGFP1-Se147 was co-expressed with selenocysteine binding protein 2 (SBP2) by either cotransfection of a second plasmid (pLuc01 system) or coexpression on the same vector (pSel system). The pLuc01 system involved co-transfection of two plasmids: the LucC258U/wtP plasmid containing a $3^{\prime}$ PHGPx SECIS element [18], and the hSBP2/V5-HIS plasmid, contained human SBP2. The pSel system utilized a dual expression in the pSelExpress1 plasmid which contains a modified Toxoplasma gondii SECIS element and the C terminal functional domain of rat SBP2 [19].

HEK293T cells were transfected with roGFP1-N1 (control vector), roGFP1-pLuc01, roGFP1-Se147pLuc01, roGFP1-pSel, or roGFP1-Se147pSel (Fig. 1a). roGFP1 was

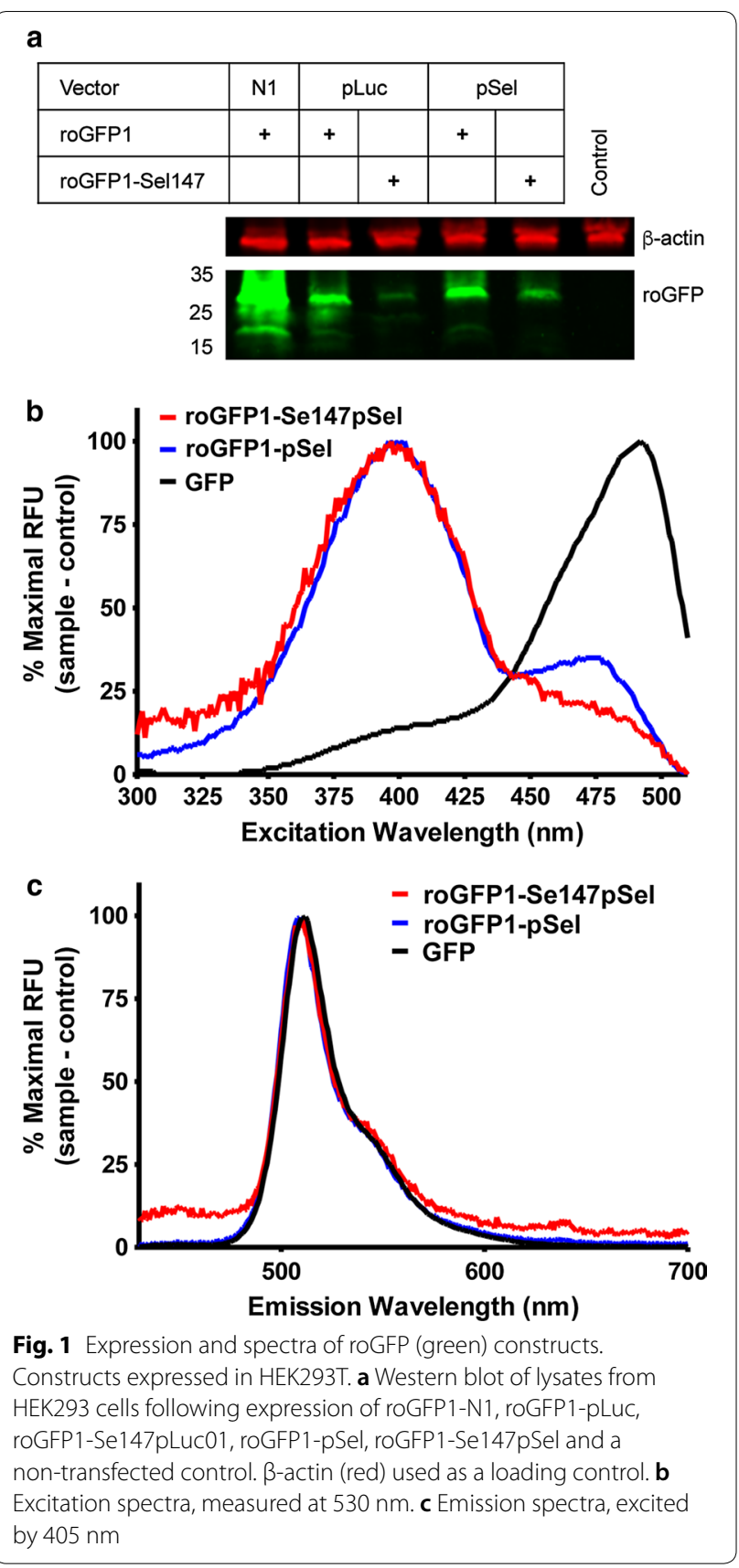

highly expressed in the control vector (roGFP1-N1) as assessed by western blot. roGFP1 expression was reduced with use of both the selenovectors (roGFP1-pSel, and roGFP1-pLuc01). Expression of roGFP1-Se147 was limited but detectable for both selenovectors, although expression was consistently higher with the roGFP1Se147pSel vector. Previous studies have demonstrated protein truncation at selenocysteine insertion sites [14, $18,19]$. However, no evidence of protein truncation was observed for the selenoproteins. 
Using transfected HEK293T cells suspended in PBS, we evaluated the excitation (detected at $530 \mathrm{~nm}$, Fig. 1b) and emission spectra (excited at $405 \mathrm{~nm}$, Fig. 1c) of GFP, roGFP1-pSel and roGFP1-Se147pSel. To account for the differences in expression efficiency (GFP $>$ roGFP1pSel $>$ roGFP1-Se147pSel), spectral data was normalized to maximal peak for each fluorescent protein. Redox-insensitive GFP exhibited a large excitation peak at $\sim 480 \mathrm{~nm}$ and roGFP1-pSel exhibited two excitation peaks with the largest peak at $\sim 405 \mathrm{~nm}$ and a smaller peak at $\sim 475 \mathrm{~nm}$, consistent with previous studies [1]. The excitation spectrum for roGFP1-Se147pSel was similar to roGFP1-pSel with its maximum at $\sim 405 \mathrm{~nm}$. All proteins exhibited similar emission spectra with a single maximum at $\sim 530 \mathrm{~nm}$.

Though expression of roGFP1-Se147pSel was limited, sufficient fluorescent signals were observed in individual HEK293 to evaluate the responsiveness of roGFP1-Se147pSel to oxidation and reduction. Individual construct-expressing cells were assessed (as previously [20]) for their 405/470 ratio during exposure to 3-300 $\mu \mathrm{M} \mathrm{H}_{2} \mathrm{O}_{2}$. Omission of sodium selenite from the culture prevented roGFP1-Se147pSel expression (data not shown). roGFP1-pSel was insensitive to oxidation with $3 \mu \mathrm{M} \mathrm{H}_{2} \mathrm{O}_{2}$, but oxidation with $30-300 \mu \mathrm{M}$ $\mathrm{H}_{2} \mathrm{O}_{2}$ evoked substantial increases in the $405 / 470$ ratio, which was reversed by the reducing agent dithiothreitol (DTT) (3 mM) (Fig. 2a, b). The selenoprotein, roGFP1Se147pSel, exhibited minor responses to oxidation with 3-300 $\mu \mathrm{M}$ hydrogen peroxide as well as to reduction with $3 \mathrm{mM}$ DTT, indicating reduced fluorophore dynamic range (Fig. 2a, c). In comparison to roGFP1pSel, roGFP1-Se147pSel exhibited an elevated baseline $405 / 470$ ratio, which increased by $\sim 5 \%$ under resting conditions until leveling off after 2 min, suggesting photoinstability of the selenoprotein.

In order to determine the redox-sensitivity of roGFP1Se147pSel while minimizing any excitation-associated photoinstability, we reduced the exposure time and frequency of the sequential excitation. As the baseline for roGFP1-Se147pSel was greater than roGFP1-pSel, we normalized results (fold change baseline) to facilitate comparison between the constructs. As before, HEK293 cells transfected with roGFP1-pSel exhibited a robust response to $\geq 30 \mu \mathrm{M} \mathrm{H}_{2} \mathrm{O}_{2}(\mathrm{p}<0.05)$, but again failed to respond to $3 \mu \mathrm{M} \mathrm{H}_{2} \mathrm{O}_{2}$ (p>0.05) (Fig. 2d). Whereas cells transfected with roGFP1-Se147pSel exhibited an increased normalized 405/470 ratio in response to $\geq 300 \mathrm{nM} \mathrm{H}_{2} \mathrm{O}_{2}(\mathrm{p}<0.05)$ (Fig. 2e). Thus the threshold for $\mathrm{H}_{2} \mathrm{O}_{2}$ detection for roGFP1-Se147pSel was approximately 100-fold lower than that of roGFP1-pSel. Curve fitting of the dose-response relationships showed that roGFP1Se147pSel was approximately 20 times more sensitive to oxidation with $\mathrm{H}_{2} \mathrm{O}_{2}$ compared to roGFP1-pSel (EC50 of $9.8 \times 10^{-7} \mathrm{M}$ and $2.0 \times 10^{-5} \mathrm{M}$, respectively) (Fig. 2f). Consistent with our previous data, roGFP1-Se147pSel demonstrated a greatly diminished dynamic range compared to roGFP1-pSel.

We next evaluated the sensitivity of the selenoprotein to endogenous ROS evoked by the mitochondrial complex III inhibitor antimycin A in HEK293 cells [21, 22]. Antimycin A $(10 \mu \mathrm{M})$ failed to increase the $405 / 470$ ratio of HEK293 transfected with roGFP1-pSel ( $>$ > 0.05, compared to untreated cells) (Fig. 2g). Whereas antimycin A increased the 405/470 ratio of HEK293 transfected with roGFP1-Se147pSel $(\mathrm{p}<0.05)$, compared to the $0.1 \%$ ethanol vehicle or untreated control) (Fig. 2h). Unexpectedly, the $0.1 \%$ ethanol vehicle decreased the roGFP1pSel $405 / 470$ ratio $(\mathrm{p}<0.01)$ but this did not occur with roGFP1-Se147pSel $(\mathrm{p}>0.05)$. Overall, the data suggest that roGFP1-Se147pSel is sufficiently sensitive to detect endogenous oxidative stress produced downstream of mitochondrial dysfunction.

Finally, cytosolic proteins were first collected from saponin-treated HEK293T cells transfected with either roGFP1-pSel or roGFP1-Se147pSel, then purified and concentrated using spin columns (10 kDa MW cutoff). We performed a redox titration using a $10 \mathrm{mM}$ lipoate buffer with increasing ratios oxidized:reduced lipoate (from 0:10 to 10:0 in increments of $1 \mathrm{mM}$ ) and fluorescent spectra were obtained, yielding the 405/470 excitation ratios. As expected the spectra for roGFP1-pSel was redox sensitive (Fig. 3a, b), with a calculated redox potential of $-289.9 \mathrm{mV}$, similar to the $-288 \mathrm{mV}$ calculated by other labs [8]. Purified roGFP1-Se147pSel was barely detected above background (Fig. 3c). Furthermore, the spectra indicated no consistent changes in 405/470 ratio throughout the titration (Fig. 3d), thus the redox potential of roGFP1-Se147 was not able to be calculated.

\section{Discussion}

The mutation of cysteine to selenocysteine (UGA) at position 147 in both selenovectors yielded a full-length protein $(\sim 27 \mathrm{kDa})$, indicating successful incorporation of the selenocysteine. We found that the pSelExpress1 vector (containing both the selenoprotein and SBP2) produced relatively more selenoprotein, consistent with its reported increased efficiency [19]. Spectral analysis revealed similar excitation and emission spectra for both roGFP1 and roGFP1-Se147, indicating that the 405/470 ratio was appropriate for determining redox-sensitivity of roGFP1-Se147. Despite the low selenoprotein expression, sufficient roGFP1-Se147 was expressed in some HEK293 cells to perform fluorescent live cell imaging. Consistent with previous reports cells transfected with roGFP1 responded robustly to substantial oxidation 


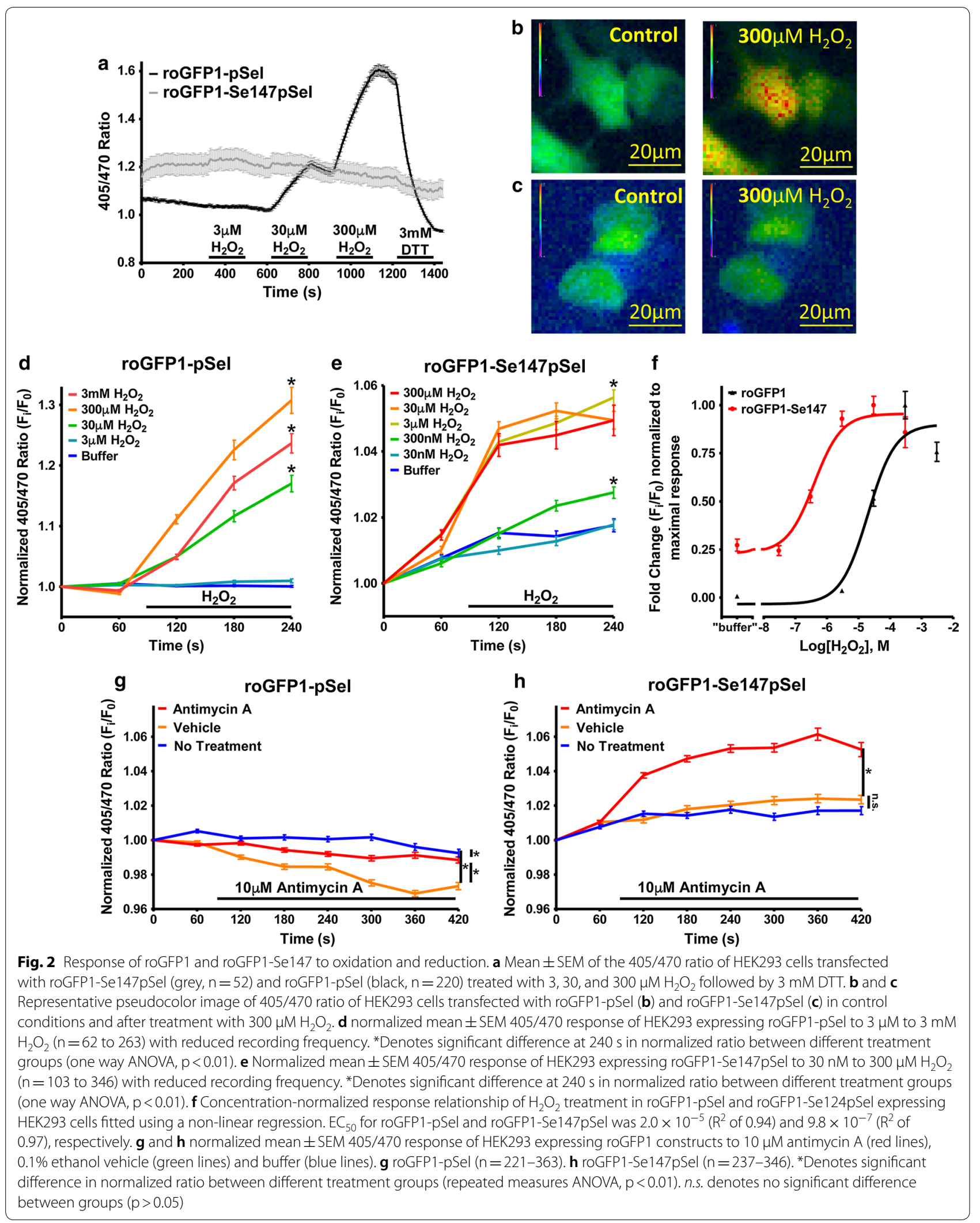



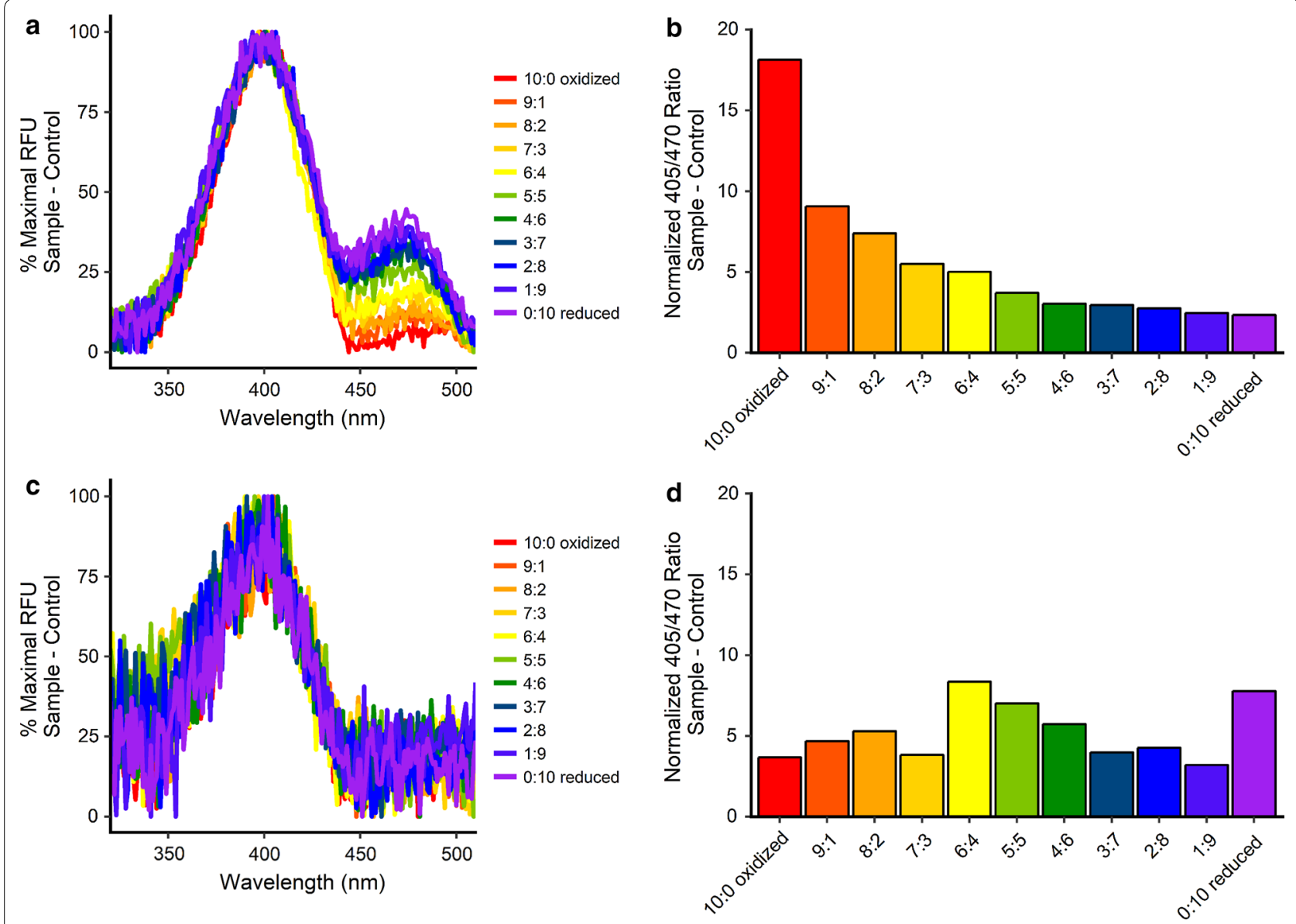

Fig. 3 Redox titration of roGFP1 and roGFP1-Se147. Constructs expressed in HEK293T. Following purification roGFP constructs were incubated with $10 \mathrm{mM}$ lipoate buffer with increasing ratios oxidized:reduced lipoate. a Normalized excitation spectra for roGFP1 in lipoate buffers. b Calculated 405/470 ratio of roGFP1 in lipoate buffers. c Normalized excitation spectra for roGFP1-Se147 in lipoate buffers. d Calculated 405/470 ratio of roGFP1-Se149 in lipoate buffers

caused by concentrations of $\geq 30 \mu \mathrm{M} \mathrm{H} \mathrm{O}_{2}$, but failed to respond to either $3 \mu \mathrm{M} \mathrm{H} \mathrm{H}_{2} \mathrm{O}_{2}$ or $10 \mu \mathrm{M}$ antimycin A [1]. Cells transfected with roGFP1-Se147 demonstrated a 100-fold lower $\mathrm{H}_{2} \mathrm{O}_{2}$ detection threshold than those transfected with roGFP1. Furthermore, cells transfected with roGFP1-Se147 demonstrated sufficient sensitivity to detect mitochondrial ROS evoked by $>30 \mathrm{~s}$ treatment with the mitochondrial complex III inhibitor antimycin A. Our previous studies have shown that antimycin A causes mitochondrial ROS production and mitochondrial depolarization within $30 \mathrm{~s}$ [23]. Thus our data indicates increased sensitivity of the selenoprotein redox sensor to oxidation with both exogenous and endogenous ROS. Consistent with its structural similarities to GFP, roGFP1-Se147 was expressed within the cytosolic compartment.

\section{Limitations}

Unfortunately, roGFP1-Se147 exhibited a decreased dynamic range and photoinstability. By decreasing the excitation exposure to roGFP1-Se147, we were able to resolve stimuli-induced responses. However, these characteristics limit the usefulness of this roGFP1-Se147 as an effective reporter. Both the diminished dynamic range and photoinstability can likely be attributed to unforeseen structural consequences resulting from the replacement of cysteine with selenocysteine. Other studies have shown that roGFP1 exhibits some photoswitching with prolonged exposure to $405 \mathrm{~nm}$ light [24]. This results in a shift toward the $470 \mathrm{~nm}$ excitation maximum independent of disulfide bond formation. It is possible that selenocysteine altered the protein structure in such a way that it worsened the existing photoinstability of roGFP1.

Most selenoproteins have a single selenocysteine residue [25]. Selenocysteine incorporation requires multiple elements including SECIS, a selenocysteine specific 
elongation factor and selenium. As such, the incorporation efficiency of selenocysteine is reduced compared to that of canonical amino acids [26-28]. Here, we found that expression levels of roGFP1-Se147 were greatly reduced but were sufficient in individual cells. Furthermore, the functionality (dynamic range, photostability) was disrupted. Previous studies have successfully inserted selenocysteine (in the place of cysteine) into proteins normally lacking selenocysteine including luciferase, rat growth hormone receptor, thyroid hormone receptor, glutaredoxin and plant phospholipid hydroperoxide glutathione peroxidase [26, 29-31]. Thus, the decreased functionality of roGFP1-Se147 is likely a specific effect on roGFP1, rather than a general property of non-native selenocysteine incorporation.

Despite the functional changes in 405/470 ratio of roGFP1-Se147 in HEK293 cells upon exposure to $\mathrm{H}_{2} \mathrm{O}_{2}$ and antimycin $\mathrm{A}$, we were unable to demonstrate redox-induced fluorescence changes in purified roGFP1-Se147. While the decreased expression of roGFP1-Se147 hindered the spectral analysis, we believe this is not solely responsible for the lack of measurable redox sensitivity. Such a state suggests that either the selenocysteine or cysteine within the redoxsensing moiety of the roGFP have become oxidized sufficiently that it is no longer sensitive to reducing agents. We have previously shown that roGFP1 loses the ability to report redox status following cysteine covalent modification by $n$-methyl-maleimide [20]. Despite selenocysteines being more sensitive to oxidation than cysteines, cysteines are more sensitive to 'over-oxidation', i.e. into sulfinic and sulfonic states, than selenocysteines [32]. Indeed, the presence of a selenocysteine may increase the 'over-oxidation' of cysteines [33]. It is possible that the roGFP1-Se147 became irreversible oxidized during the extraction/purification protocol. Without a redox titration of roGFP1-Se147, we cannot prove that this particular roGFP construct is directly modified by redox environment. As such, we have no mechanistic evidence that the increased sensitivity of changes in 405/470 ratio of roGFP1-Se147 in HEK293 cells upon exposure to low levels of $\mathrm{H}_{2} \mathrm{O}_{2}$ is due to a shift in the redox potential of the redox-sensing moiety.

In conclusion, we present a selenocysteine-containing mutant of roGFP1 that displays an apparent increased sensitivity to ROS but also has decreased dynamic range and photoinstability. The development of probes with increased sensitivity is a pre-requisite for the understanding of the multiple roles of ROS and oxidative stress in physiological and pathophysiological processes.

\section{Additional file}

Additional file 1. Supplemental methods. Further details of the methods used in this study.

\section{Authors' contributions}

KRS and TTC designed the study. KRS, JMA, PKB and SHH performed the experiments. KRS and TTC wrote the manuscript. All authors reviewed the manuscript. All authors read and approved the final manuscript.

\section{Acknowledgements}

The authors would like to thank Dr. SJ Remington (University of Oregon), Dr. P Copeland (Rutgers University) and Dr. V Gladyshev (Brigham and Women's Hospital, Harvard Medical School) for their generous plasmid gifts. This work was supported by the National Heart Lung \& Blood Institute (R01HL119802).

\section{Competing interests}

The authors declare that they have no competing interests.

\section{Availability of data/materials}

The datasets used and analyzed during the current study are available from the corresponding author on reasonable request.

\section{Consent for publication}

All authors consent to the submission of this manuscript. No patient data are included, thus the images and any other information will not compromise anonymity.

\section{Ethical approval and consent to participate}

Not applicable.

\section{Funding}

This work was funded by the National Institutes of Health R01HL119802. The funding body contributed financial support but did not participate directly in the design, data collection, analysis, interpretation and writing of this study/ manuscript.

\section{Publisher's Note}

Springer Nature remains neutral with regard to jurisdictional claims in published maps and institutional affiliations.

Received: 8 October 2018 Accepted: 13 November 2018 Published online: 22 November 2018

\section{References}

1. Dooley CT, Dore TM, Hanson GT, Jackson WC, Remington SJ, Tsien RY. Imaging dynamic redox changes in mammalian cells with green fluorescent protein indicators. J Biol Chem. 2004;279(21):22284-93.

2. Chen X, Tian X, Shin I, Yoon J. Fluorescent and luminescent probes for detection of reactive oxygen and nitrogen species. Chem Soc Rev. 2011;40(9):4783-804

3. Guo H, Aleyasin H, Dickinson BC, Haskew-Layton RE, Ratan RR. Recent advances in hydrogen peroxide imaging for biological applications. Cell Biosci. 2014;4(1):64.

4. Breckwoldt MO, Pfister FM, Bradley PM, Marinkovic P, Williams PR, Brill MS, et al. Multiparametric optical analysis of mitochondrial redox signals during neuronal physiology and pathology in vivo. Nat Med. 2014;20(5):555-60.

5. Wagener KC, Kolbrink B, Dietrich K, Kizina KM, Terwitte LS, Kempkes $B$, et al. Redox indicator mice stably expressing genetically encoded neuronal roGFP: versatile tools to decipher subcellular redox dynamics in neuropathophysiology. Antioxid Redox Signal. 2016;25(1):41-58.

6. Waypa GB, Marks JD, Guzy R, Mungai PT, Schriewer J, Dokic D, et al. Hypoxia triggers subcellular compartmental redox signaling in vascular smooth muscle cells. Circ Res. 2010;106(3):526-35. 
7. Roma LP, Duprez J, Takahashi HK, Gilon P, Wiederkehr A, Jonas JC. Dynamic measurements of mitochondrial hydrogen peroxide concentration and glutathione redox state in rat pancreatic beta-cells using ratiometric fluorescent proteins: confounding effects of $\mathrm{pH}$ with HyPer but not roGFP1. Biochem J. 2012;441(3):971-8.

8. Hanson GT, Aggeler R, Oglesbee D, Cannon M, Capaldi RA, Tsien RY, et al Investigating mitochondrial redox potential with redox-sensitive green fluorescent protein indicators. J Biol Chem. 2004;279(13):13044-53.

9. Roberts DD, Lewis SD, Ballou DP, Olson ST, Shafer JA. Reactivity of small thiolate anions and cysteine-25 in papain toward methyl methanethiosulfonate. Biochemistry. 1986;25(19):5595-601.

10. Cannon MB, Remington SJ. Re-engineering redox-sensitive green fluorescent protein for improved response rate. Protein Sci. 2006;15(1):45-57.

11. Byun BJ, Kang YK. Conformational preferences and pK(a) value of selenocysteine residue. Biopolymers. 2011;95(5):345-53.

12. Muller S, Senn H, Gsell B, Vetter W, Baron C, Bock A. The formation of diselenide bridges in proteins by incorporation of selenocysteine residues: biosynthesis and characterization of (Se)2-thioredoxin. Biochemistry. 1994;33(11):3404-12.

13. Chambers I, Frampton J, Goldfarb P, Affara N, McBain W, Harrison PR. The structure of the mouse glutathione peroxidase gene: the selenocysteine in the active site is encoded by the 'termination' codon, TGA. EMBO J. 1986;5(6):1221-7.

14. Tujebajeva RM, Copeland PR, Xu XM, Carlson BA, Harney JW, Driscoll DM, et al. Decoding apparatus for eukaryotic selenocysteine insertion. EMBO Rep. 2000;1(2):158-63.

15. Zinoni F, Heider J, Bock A. Features of the formate dehydrogenase mRNA necessary for decoding of the UGA codon as selenocysteine. Proc Natl Acad Sci USA. 1990;87(12):4660-4

16. Copeland PR, Fletcher JE, Carlson BA, Hatfield DL, Driscoll DM. A novel RNA binding protein, SBP2, is required for the translation of mammalian selenoprotein mRNAs. EMBO J. 2000;19(2):306-14.

17. Copeland PR, Stepanik VA, Driscoll DM. Insight into mammalian selenocysteine insertion: domain structure and ribosome binding properties of Sec insertion sequence binding protein 2. Mol Cell Biol. 2001;21(5):1491-8.

18. Mehta A, Rebsch CM, Kinzy SA, Fletcher JE, Copeland PR. Efficiency of mammalian selenocysteine incorporation. J Biol Chem. 2004;279(36):37852-9.

19. Novoselov SV, Lobanov AV, Hua D, Kasaikina MV, Hatfield DL, Gladyshev $V N$. A highly efficient form of the selenocysteine insertion sequence element in protozoan parasites and its use in mammalian cells. Proc Natl Acad Sci USA. 2007;104(19):7857-62.

20. Bahia PK, Parks TA, Stanford KR, Mitchell DA, Varma S, Stevens SM Jr, et al. The exceptionally high reactivity of Cys 621 is critical for electrophilic activation of the sensory nerve ion channel TRPA1. J Gen Physiol. 2016;147(6):451-65.

21. Turrens JF, Alexandre A, Lehninger AL. Ubisemiquinone is the electron donor for superoxide formation by complex III of heart mitochondria. Arch Biochem Biophys. 1985;237(2):408-14.

22. Gyulkhandanyan AV, Pennefather PS. Shift in the localization of sites of hydrogen peroxide production in brain mitochondria by mitochondrial stress. J Neurochem. 2004;90(2):405-21.

23. Stanford KR, Taylor-Clark TE. Mitochondrial modulation-induced activation of vagal sensory neuronal subsets by antimycin A, but not CCCP or rotenone, correlates with mitochondrial superoxide production. PLoS ONE. 2018;13(5):e0197106.

24. Schwarzlander M, Fricker MD, Muller C, Marty L, Brach T, Novak J, et al. Confocal imaging of glutathione redox potential in living plant cells. J Microsc. 2008;231(2):299-316.

25. Kryukov GV, Castellano S, Novoselov SV, Lobanov AV, Zehtab O, Guigo $\mathrm{R}$, et al. Characterization of mammalian selenoproteomes. Science. 2003;300(5624):1439-43.

26. Leonard JL, Leonard DM, Shen Q, Farwell AP, Newburger PE. Seleniumregulated translation control of heterologous gene expression: normal function of selenocysteine-substituted gene products. J Cell Biochem. 1996;61(3):410-9.

27. Lesoon A, Mehta A, Singh R, Chisolm GM, Driscoll DM. An RNA-binding protein recognizes a mammalian selenocysteine insertion sequence element required for cotranslational incorporation of selenocysteine. Mol Cell Biol. 1997;17(4):1977-85.

28. Gonzalez-Flores JN, Shetty SP, Dubey A, Copeland PR. The molecular biology of selenocysteine. Biomol Concepts. 2013;4(4):349-65.

29. Latreche L, Jean-Jean O, Driscoll DM, Chavatte L. Novel structural determinants in human SECIS elements modulate the translational recoding of UGA as selenocysteine. Nucleic Acids Res. 2009;37(17):5868-80.

30. Ge Y, Qi Z, Wang Y, Liu X, Li J, Xu J, et al. Engineered selenium-containing glutaredoxin displays strong glutathione peroxidase activity rivaling natural enzyme. Int J Biochem Cell Biol. 2009;41(4):900-6.

31. Hazebrouck S, Camoin L, Faltin Z, Strosberg AD, Eshdat Y. Substituting selenocysteine for catalytic cysteine 41 enhances enzymatic activity of plant phospholipid hydroperoxide glutathione peroxidase expressed in Escherichia coli. J Biol Chem. 2000;275(37):28715-21.

32. Snider GW, Ruggles E, Khan N, Hondal RJ. Selenocysteine confers resistance to inactivation by oxidation in thioredoxin reductase: comparison of selenium and sulfur enzymes. Biochemistry. 2013;52(32):5472-81.

33. Dillard CJ, Tappel AL. Mercury, silver, and gold inhibition of seleniumaccelerated cysteine oxidation. J Inorg Biochem. 1986;28(1):13-20.
Ready to submit your research? Choose BMC and benefit from:

- fast, convenient online submission

- thorough peer review by experienced researchers in your field

- rapid publication on acceptance

- support for research data, including large and complex data types

- gold Open Access which fosters wider collaboration and increased citations

- maximum visibility for your research: over $100 \mathrm{M}$ website views per year

At BMC, research is always in progress.

Learn more biomedcentral.com/submissions 